\title{
Editorial
}

\section{Poor nutrition-related policies and practices of global food companies under the spotlight}

Several papers in the current issue of Public Health Nutrition highlight important issues with respect to practices of food companies and public health nutrition in different countries.

A number of papers investigate the sodium content of processed and fast foods. Prentice et al. ${ }^{(1)}$ report on the high sodium content of fast foods in New Zealand. Similarly, Kraemer et al. ${ }^{(2)}$ describe the high sodium content of processed foods in Brazil and identify substantial potential for reducing sodium levels in most food products. Saavedra-Garcia et al. ${ }^{(3)}$ examine the feasibility of salt reduction in bread. Encouragingly, their study in Peru demonstrates that the introduction of bread with a $20 \%$ reduction in salt is feasible without affecting bakery sales. These findings are supported by the study by Quilez et $a l{ }^{(4)}$ in Spain who found that efforts to reduce salt in bread by $27 \%$ did not deter product sales.

Two papers investigate health and nutrition claims on packaged foods. Kaur et al. $^{(5)}$ found that the nutrient profile of products carrying claims in the UK was only marginally healthier than for similar products without claims, suggesting that claims may have some, albeit limited, informational value. Mayhew et al. ${ }^{(6)}$ found that chip and sweet biscuit packages in countries with health and nutrition claim regulations had a higher number of claims and promotional marketing techniques directed at children than in countries without such regulations. In their study of another aspect of product packaging and labelling, Poelman et al. ${ }^{(7)}$ found substantial inconsistency in package sizes and manufacturer-recommended serving sizes of sweet beverages within and between four highincome countries, and they call for serving size regulations that would provide consistency and assist individuals in making healthier food choices.

Given that the principal objective of a company is to maximise shareholder value ${ }^{(8)}$, a key challenge for public health policy makers and civil society organisations seeking to engage with food companies is to understand the many and varied factors that company executives take into account in seeking to maximise shareholder value. These factors potentially include competition from other companies in the supply chain, demand for substitute products, stakeholder perceptions, and environmental and social issues ${ }^{(9,10)}$. Greater understanding of these influences can help predict corporate behaviour and identify opportunities for companies to meet their objectives in ways that are consistent with public health goals. It can also contribute to the identification of specific areas where voluntary company action is unlikely and government legislation is necessary.

The importance of monitoring food companies and holding them to account for their nutrition policies and practices is the rationale behind the Access to Nutrition Index (ATNI) ${ }^{(11)}$. ATNI measures and benchmarks the nutrition-related commitments, performance and disclosure practices of food and beverage manufacturers to enable comparison of company performance with reference to international norms and standards. ATNI is published by the Access to Nutrition Foundation, an independent non-profit organisation based in the Netherlands, funded by the Bill \& Melinda Gates Foundation, the Wellcome Trust and the Children's Investment Fund Foundation. The ATNI methodology was developed with input from a wide range of stakeholders including academics, policy makers and representatives from non-government organisations, the food industry and investment firms. The recently released 2016 ATNI assessed twenty-two of the largest international food and beverage corporations in eight domains including their nutrition governance and management, their approach to formulating and delivering products, and their efforts to influence consumer choice and behaviour. This assessment was based on information in the public domain and other information provided directly by companies, some of which is subject to non-disclosure agreements, as part of the ATNI research process.

The overall results of the 2016 ATNI assessment are dominated by low scores. Only two companies had an overall summary score above 5 on a 10-point scale and the majority of companies scored below 3. These results indicate that, across the board, the world's largest food and beverage manufacturers are falling far short of the public health community's expectations with respect to their nutrition commitments, practices and public disclosure, with substantial room for improvement. While some companies performed reasonably well (above 7) in particular domains (such as product formulation and responsible marketing), companies generally scored lowest on labelling (information display, health and nutrition claims made) and on accessibility (pricing and distribution) of healthy products. Companies also performed poorly with respect to their engagement with stakeholders, and particularly in regard to their lobbying and influence on governments and policy makers. While direct comparison with the inaugural (2013) ATNI assessment ${ }^{(12)}$ is not 
possible due to changes in the methodology, the overall pattern is that there has been little improvement from major food companies over the last three years in the areas investigated by ATNI.

The intended audience for the ATNI results includes food companies, investors, policy makers, civil society organisations, academics and the media. ATNI's strong engagement with the investment community is particularly significant, given that, as a major influencer of share prices globally, the investment community is a potentially powerful agent to drive changes in corporate behaviours. To date, more than forty investment firms, collectively managing over \$US 3 trillion in assets, have signed the ATNI Investor Statement ${ }^{(13)}$. The notion that investors would use an assessment of nutrition-related corporate practices to inform investment decisions is compelling from a public health perspective. Indeed, major investors could represent a highly significant lever for non-communicable disease (NCD) prevention efforts, particularly given the current political environment in many countries, in which the implementation of recommended public health regulations (such as restrictions on the marketing of unhealthy foods to children and taxes on unhealthy food products) has been very limited ${ }^{(14)}$.

While the efforts of ATNI are to be encouraged, we note several important limitations to the ATNI approach. First, the assessment methodology relies heavily on information provided by companies that is not in the public domain. While the design of ATNI strongly encourages improved public disclosure of company policies and practices, limitations in the availability of data makes objective assessment more difficult. Accordingly, greater transparency from companies is needed to strengthen ATNI and other monitoring initiatives, and the public health community needs to focus advocacy efforts in this area. Second, the ATNI approach is highly resource-intensive to implement. In practice, this limits the number of companies and geographic scope that can be assessed by ATNI. While ATNI is planning to publish a small number of country-level assessments (spotlight indexes), efforts to monitor and benchmark companies in a large number and broad range of countries are likely to need assessment tools that are cheaper to implement. In addition, ATNI assesses only food and beverage manufacturers, and not other sectors of the food industry, such as retailers and fast-food chains. Finally, ATNI addresses corporate efforts to influence public policy (often referred to as corporate political activity, CPA) in only a limited way. CPA of food companies has been identified as a potential risk to public health and it is therefore critical to monitor these practices closely ${ }^{(15)}$. While the ATNI methods include an assessment of self-disclosed company lobbying practices, a more complete assessment of CPA would include practices such as their financial support for political parties, the way they shape the evidence base (for example, through the funding of research) and the way they frame the debate on nutrition-related issues. Future monitoring efforts, such as those planned by INFORMAS (International Network for Food and Obesity/NCDs Research, Monitoring and Action Support) ${ }^{(15)}$ aim to be less resource-intensive and will include other sectors of the food industry and a more comprehensive assessment of CPA. The latter, however, needs to be trialled in a number of countries and include clear assessment criteria ${ }^{(16)}$

While it is well recognised that the private sector has an important role to play in efforts to address obesity and diet-related $\operatorname{NCD}^{(17,18)}$, there is clearly substantial scope for major food and beverage companies to improve their nutrition-related practices. It is hypothesised that initiatives such as ATNI that seek to improve the accountability of food companies will ultimately lead to better performance of companies as part of global efforts to enhance population nutrition. However, this is likely to rely on sustained engagement from food companies as part of the process; close involvement from a wide range of stakeholders, including major investors; and, particularly in cases where voluntary food industry action has proved insufficient, the political will and commitment to make necessary changes to government regulation.

\section{Acknowledgements}

G.S. is a researcher within the Australian National Health and Medical Research Council (NHMRC) Centre for Research Excellence in Obesity Policy and Food Systems (APP1041020), and is the recipient of an Australian Research Council Discovery Early Career Researcher Award (project number DE160100307).

Gary Sacks
World Health Organization Collaborating
Centre for Obesity Prevention, Deakin University
Geelong, Australia
Email gary.sacks@deakin.edu.au
Stefanie Vandevijvere
Deputy Editor
The University of Auckland
School of Population Health
Auckland, New Zealand

\section{References}

1. Prentice CA, Smith C \& McLean RM (2016) Sodium in commonly consumed fast foods in New Zealand: a public health opportunity. Public Health Nutr 19, 958-966.

2. Kraemer MV, Oliveira RC, Gonzalez-Chica DA et al. (2016) Sodium content on processed foods for snacks. Public Health Nutr 19, 967-975.

3. Saavedra-Garcia L, Sosa-Zevallos V, Diez-Canseco F et al. (2016) Reducing salt in bread: a quasi-experimental feasibility study in a bakery in Lima, Peru. Public Health Nutr 19, 976-982.

4. Quilez J \& Salas-Salvado J (2016) The feasibility and acceptability of reducing salt in partially baked bread: a Spanish case study. Public Health Nutr 19, 983-987. 
5. Kaur A, Scarborough P, Matthews A et al. (2016) How many foods in the UK carry health and nutrition claims, and are they healthier than those that do not? Public Health Nutr 19, 988-997.

6. Mayhew AJ, Lock K, Kelishadi R et al. (2016) Nutrition labelling, marketing techniques, nutrition claims and health claims on chip and biscuit packages from sixteen countries. Public Health Nutr 19, 998-1007.

7. Poelman MP, Eyles H, Dunford E et al. (2016) Package size and manufacturer-recommended serving size of sweet beverages: a cross-sectional study across four high-income countries. Public Health Nutr 19, 1008-1016.

8. Friedman M (1970) The social responsibility of business is to increase its profits. New York Times Magazine 13 September, 1-6.

9. Porter M (1979) How competitive forces shape strategy. Harvard Bus Rev Mar-Apr issue 137-145.

10. Porter M \& Kramer M (2011) Creating shared value: how to reinvent capitalism - and unleash a wave of innovation and growth. Harvard Bus Rev Jan-Feb issue 1-7.

11. Access to Nutrition Index ${ }^{\mathrm{TM}}$ (2016) Access to Nutrition Index: Global Index 2016. https://www.accesstonutrition. org/sites/2016.atnindex.org/files/atni-global-index-2016_2. pdf (accessed 16 February 2016).

12. Access to Nutrition Index ${ }^{\mathrm{TM}}$ (2013) Access to Nutrition Index: Global Index 2013. http://s3.amazonaws.
com/ATN/atni_global_index_2013.pdf (accessed 16 February 2016).

13. Access to Nutrition Index ${ }^{\mathrm{TM}}$ (2013) Access to Nutrition Index Investor Statement. https://www.accesstonutrition. org/sites/www.accesstonutrition.org/files/atni_investor_ statement_20130310.pdf (accessed 24 February 2016).

14. Swinburn B, Kraak V, Rutter H et al. (2015) Strengthening accountability systems to create healthy food environments and reduce global obesity. Lancet $\mathbf{3 8 5}$, 2534-2545.

15. Mialon M, Swinburn B \& Sacks G (2015) A proposed approach to systematically identify and monitor the corporate political activity of the food industry with respect to public health using publicly available information. Obes Rev 16, 519-530.

16. Sacks G, Swinburn B, Kraak V et al. (2013) A proposed approach to monitor private-sector policies and practices related to food environments, obesity and noncommunicable disease prevention. Obes Rev 14, Suppl. 1, $38-48$.

17. World Health Organization (2004) Global Strategy on Diet, Physical Activity and Health. Geneva: WHO.

18. United Nations General Assembly (2011) Political Declaration of the High-level Meeting of the General Assembly on the Prevention and Control of Noncommunicable Diseases. New York: UN. 